Jurnal Keperawatan Silampari

Volume 5, Nomor 1, Desember 2021

e-ISSN: 2581-1975

p-ISSN: 2597-7482

DOI: https://doi.org/10.31539/jks.v5i1.2424

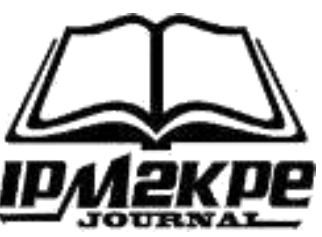

\title{
INTERPROFESSIONAL EDUCATION (IPE) DALAM KEPERAWATAN
}

\author{
Nunung Siti Sukaesih ${ }^{1}$, Hikmat Pramajati ${ }^{2}$, Titin Sutini ${ }^{3}$, \\ Emi Lindayani ${ }^{4}$, Sri Wulan Lindasari ${ }^{5}$ \\ Universitas Pendidikan Indonesia ${ }^{1,2,4,5}$ \\ Universitas Padjadjaran ${ }^{3}$ \\ nunungss@upi.edu ${ }^{1}$
}

\begin{abstract}
ABSTRAK
Penelitian ini bertujuan untuk melengkapi data artikel yang berkaitan dengan pendidikan interprofesional dalam keperawatan sehingga dapat diperoleh data yang akurat dan komprehensif dan diharapkan dapat dijadikan sebagai dasar penelitian selanjutnya, khususnya dalam pengembangan pendidikan interprofesional. Metode penelitian yang berhubungan dengan pendidikan interprofesi dalam bidang perawatan dari 2010-2019 berdasarkan data dari Scopus, dengan menggunakan aplikasi pencarian Publish or Perish (POP), dan menggunakan metode analitis konten secara sistematis. Hasil penelitian menunjukkan bahwa jumlah publikasi artikel telah meningkat setiap tahun. Ini menunjukkan bahwa kompetensi interprofesional dalam pendidikan keperawatan mendapat perhatian lebih dari para ilmuwan dan peneliti. Simpulan, ada peningkatan dalam penelitian cenderung dengan topik ini setiap tahun. Hasil penelusuran tertinggi dari kutipan per artikel adalah 132, dengan jurnal yang menerbitkan pendidikan interprofesi yang paling yang digunakan adalah bibliometrik, diharapkan dapat melihat peta penelitian secara global banyak adalah Journal of Interprofessional Care.
\end{abstract}

Kata Kunci: Belajar, Bibliometrik, Pendidikan Interprofesi, Perawat

\section{ABSTRACT}

This study aims to complete data articles related to interprofessional education in nursing so that accurate and comprehensive data can be obtained and are expected to be used as the basis for further research, especially in the development of interprofessional education. Research methods related to interprofessional education in nursing from 2010-2019 are based on data from Scopus, using the Publish or Perish (POP) search application, and using content analysis methods systematically. The results showed that the number of article publications had increased every year. This indicates that interprofessional competence in nursing education gets more attention from scientists and researchers. In conclusion, there is an increase in research tending to this topic every year. The highest search results of citations per article are 132. The journal that publishes interprofessional education the most used is bibliometrics. It is expected to see a map of research globally. Many are Journal of Interprofessional Care.

Keywords: Learning, Bibliometrics, Interprofessional Education, Nurse 


\section{PENDAHULUAN}

Kemampuan interprofesional adalah salah satu dari sekian banyak kompetensi yang harus dimiliki setiap profesi kesehatan yang diinisiasi oleh World Health Oranization (WHO), agar pelayanan kesehatan yang diberikan kepada pasien tidak terfragmentasi. Diyakini bahwa keberadaan pelayanan kesehatan komprehensif akan berdampak pada sistem kesehatan yang harus lebih baik dan menghasilkan pelayanan kesehatan yang komprehensif dan paripurna (Homeyer et al., 2018). Hal tersebut didasari oleh masalah kesehatan pada saat ini yang semakin kompleks dan untuk meningkatkan kepuasan tim kesehatan dalam bekerjasama menangani masalah kesehatan pasien (Blaževičienè et al., 2021). Selain itu, kolaborasi interprofesional telah didorong sebagai alur untuk meningkatkan pelayanan perawatan pasien (Vestergaard \& Nørgaard, 2018). Kebutuhan akan pelayanan kesehatan yang menyeluruh seperti preventif, kuratif, rehabilitatif dan promotif, akan sulit jika hanya dilakukan oleh dokter atau salah satu profesi kesehatan saja. Seluruh profesi kesehatan harus bekerja sama untuk memahami pelayanan kesehatan yang komprehensif di seluruh tatanan perawatan kesehatan, untuk memperoleh hasil yang maksimal (Lestari, 2018). Implementasi kolaborasi interprofesional pada pelayanan kesehatan sangat memungkinkan terjadi hambatan, sehingga WHO merekomendasikan agar IPE diberikan pada saat proses pendidikan berlangsung. Situasi ini meningkatkan antusiasme semua pendidikan profesi kesehatan untuk memasukkan kompetensi pendidikan antar profesional ke dalam kurikulum pendidikan mereka dan mengembangkan penelitian terkait hal ini.

Kompetensi dalam interprofessional education meliputi kompetensi tim dan kerjasana tim, peran dan tanggung jawab masing-masing profesi, serta komunikasi interprofessional (Christopher et al., 2021). Praktik kolaborasi interprofessional juga merupakan serangkaian kegiatan seperti praktik interdependen dari berbagi profesi yang berbeda, penghargaan atas kerja orang lain, berbagi informasi, tujuan, nilai tanggung jawab dengan tim kesehatan lain dalam merawat pasien, keluarga, maupun masyarakat dan berfokus pada kebutuhan pasien (Peduzzi et al., 2019).

Berdasarkan keadaan yang telah dipaparkan sebelumnya tersebut maka penelitian ini akan membahas pendidikan interprofesional dalam keperawatan dengan pendekatan studi bibliometrik. Hal ini dikarenakan perawat merupakan profesi kesehatan yang harus mampu bekerja secara mandiri, selain itu juga harus memiliki kemampuan bekerja sama dengan berbagai tim kesehatan lainnya secara profesional. Penelitian terbaru yang berkaitan dengan sikap mahasiswa kesehatan, yaitu perawat, terapis okupasi, dan terapis fisik terhadap IPE, menemukan bahwa persepsi siswa keperawatan tentang kerja sama dengan profesi lain dan kompetensi serta otonomi mereka rasakan dalam profesinya sedikit lebih rendah daripada mahasiswa profesi kesehatan lainnya (Bar et al., 2017).

Dalam studi lain, simulasi IPE yang dilakukan pada mahasiswa keperawatan dan farmasi menghasilkan bahwa mahasiswa berpendapat ketika mereka bekerja sama dengan profesi kesehatan lain merupakan salah satu kompetensi yang sangat diperlukan dan mereka juga percaya bahwa dengan memiliki kompetensi tersebut maka pasien akan merasa lebih puas akan pelayanan kesehetan yang diberikan. Tetapi mereka juga merasa kebingungan dengan peran masing-masing pada saat praktik kolaborasi interprofesi dan menunjukkan bahwa rotasi klinis bukanlah sistem pengaturan yang ideal untuk interaksi profesional pertama kalinya dengan profesi kesehatan lain (Iverson et al., 2018). 
Systematic review tentang pendidikan interprofesional dan kolaborasi di antara mahasiswa dan profesi kesehatan pada tahun 2007-2017 menemukan bahwa terdapat 17 dari 19 studi (89\%) yang menilai perubahan sikap terhadap disiplin ilmu dan nilai lain yang ditempatkan pada pendekatan berbasis tim untuk meningkatkan perawatan pasien, menemukan peningkatan kemampuan kolaborasi yang signifikan secara statistik. Tujuh studi diantaranya menilai adanya perubahan perilaku kolaboratif yang signifikan secara statistik (Spaulding et al., 2021).

Berdasarkan pencarian artikel dengan menggunakan database Scopus pada tahun 2010 hingga 2019, tidak ditemukan satu pun artikel dengan menggunakan pendekatan studi bibliometrik, yang berkaitan dengan pendidikan interprofesional dalam keperawatan. Jenis studi bibliografi ini penting, karena konsep bibliografi telah mendapatkan reputasi yang lebih relevan di bidang penelitian dan sejajar dengan jenis penelitian lain, penelitian ilmiah ini dapat dilakukan dengan cara yang lebih dapat diandalkan dengan menganalisis jumlah publikasi dan frekuensi kutipan artikel sesuai dengan tema atau topik terkait (Fernáández Batanero et al., 2019; Julia et al., 2020).

Tujuan penelitian ini adalah untuk melengkapi data artikel yang berkaitan dengan pendidikan interprofesional dalam keperawatan sehingga dapat diperoleh data yang akurat dan komprehensif dan diharapkan dapat dijadikan sebagai dasar penelitian selanjutnya, khususnya dalam pengembangan pendidikan interprofesional. Berbeda dari penelitian sebelumnya, penelitian ini adalah melakukan analisis bibliometri pada artikel yang sudah didapatkan berdasarkan hasil pencarian yang sesuai dengan kata kunci yang diharapkan yaitu pendidikan interprofesional dalam keperawatan dengan menunjukkan tujuh karakteristik, yaitu tren publikasi, jurnal yang paling banyak mempublikasikan artikel, pola kutipan, kata kunci penulis, tren dalam hubungan antara pendidikan interprofesional dalam keperawatan dan profesi kesehatan lainnya dan statistik negara dari penulis yang menerbitkan pendidikan interprofesional dalam keperawatan. Oleh karena itu, penelitian dilakukan berdasarkan rumusan masalah sebagai berikut; Q1: Bagaimana tren publikasi artikel tentang pendidikan interprofessional pada tahun 20102019?; Q2: Jurnal manakah yang telah menerbitkan artikel terbanyak tentang pendidikan interprofesional dalam keperawatan pada tahun 2010-2019?; Q3: Bagaimana pola kutipan dalam artikel tentang pendidikan interprofessional dalam keperawatan pada tahun 2010-2019 ?; Q4: Kata kunci apa saja yang sering digunakan oleh penulis dalam artikel pendidikan interprofessional dalam keperawatan pada tahun 2010-2019?; Q5: Profesi kesehatan apa yang sering dihubungkan dengan perawat dalam artikel tentang pendidikan Pendidikan interprofessional dalam keperawatan pada tahun 20102019?; Q6: Negara mana yang paling banyak menerbitkan artikel terkait pendidikan interprofesional dalam keperawatan pada tahun 2010-2019?

Pertanyaan penelitian tersebut perlu dijawab berdasarkan metode ilmiah agar kita mengetahui seberapa banyak penelitian tentang IPE dalam pendidikan keperawatan. Langkah ilmiah untuk mengetahui artikel yang relevan adalah dengan studi bibliometric. Sejauh penelusuran peneliti, belum pernah ada studi bibliometric terkait topik IPE dalam pendidikan keperawatan, meskipun penelitian tentang IPE sudah banyak diteliti.

\section{METODE PENELITIAN}

Metode penelitian yang digunakan adalah studi bibliometrik dengan menjelaskan hasil pencarian artikel melalui pemetaan terstruktur dan eksplisit. Langkah- langkah dalam pengumpulan data yang digunakan dalam studi bibliometrik dalam terdiri dari 
empat langkah yaitu; (1) prosedur pencarian data; (2) penyaringan data bibliografik; (3) melengkapi data bibliografik; (4) analisis data bibliografik.

\section{Prosedur Pencarian Data}

Penelitian ini menggunakan perangkat lunak Publish or Perish (POP) sebagai aplikasi untuk mencari metadata untuk artikel yang diterbitkan dari tahun 2010-2019 menggunakan kata kunci yang sebelumnya telah dibahas dan memilih sumber metadata dari Scopus yang merupakan sumber metadata terbesar dan paling tepercaya dan memilih dan menyediakan data dengan rentang waktu yang cukup lama dari tahun 1996 hingga masa depan. Terdapat beberapa kriteria telah dipilih untuk menyusun semua bibliografi dalam penelitian ini termasuk dalam proses analisis yang dilakukan, diantaranya adalah memenuhi tiga karakteristik sebagai berikut; (1) bentuk bibliografi yang akan dianalisis adalah artikel dalam jurnal termasuk artikel asli dan systematic review; (2) judul, abstrak atau kata kunci artikel harus berisi pendidikan interprofesional dan keperawatan; (3) tahun pencarian artikel yang di publikasi dibatasi pada periode tahun 2010-2019 (10 tahun terakhir). Pencarian pada di fokuskan pada database Scopus melalui aplikasi POP dibatasi hingga maksimum 200 artikel per kali satu pencarian sehingga pencarian dibagi menjadi setiap tahun, oleh karena itu, pencarian bibliografi dilakukan per tahun pada bulan November 2020. Gambar 1 merupakan tampilan dari metode pencarian bibliografi dalam aplikasi POP.

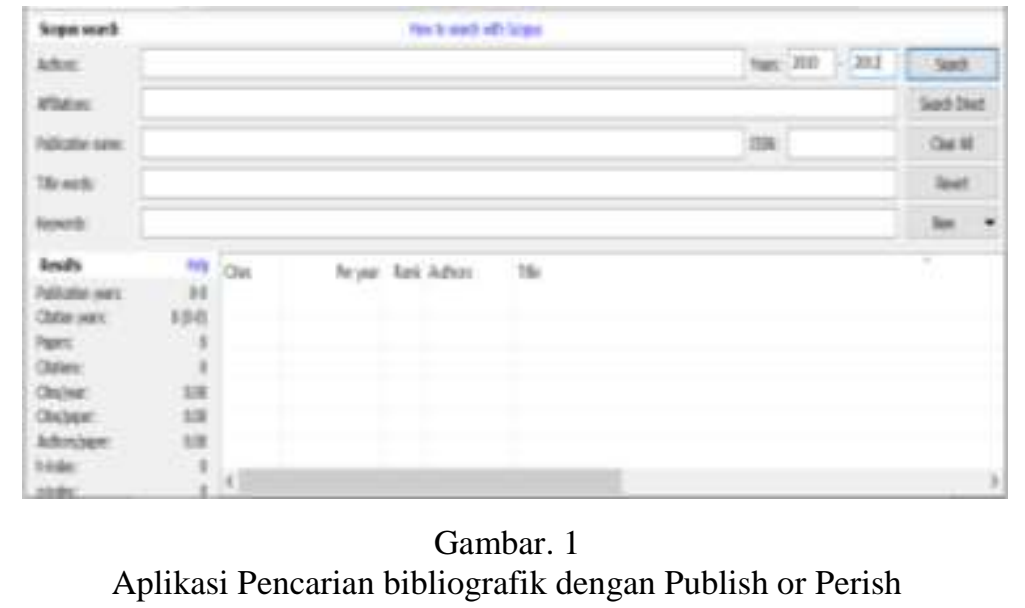

Hasil pencarian data bibliometrik yang menggunakan perangkat lunak POP disimpan dalam bentuk file Bibtext dan Microsoft Excel. File Bibtext diperlukan untuk mengimpor data ke Mendeley sementara file Microsoft Excel digunakan untuk mengedit data secara manual.

\section{Penyaringan Data Bibliografik}

Pemilihan dan pengkategorian bibliografik ditentukan dengan menggunakan beberapa standar, yaitu; (1) artikel yang berisi tentang pendidikan interprofesional dan keperawatan; (2) artikel yang dipublikasikan dengan bahasa Inggris; (3) artikel yang diterbitkan oleh publisher yang mapan dan terkemuka. Setiap bibliografi yang dipilih atau dikecualikan dalam proses analisis bibliometrik, diperiksa dengan menguraikannya ke dalam database Scopus dan dihapus dari aplikasi POP. Jenis bibliografi yang diambil dalam studi ini adalah hanya jenis jurnal. Beberapa bibliografi yang didapatkan dalam proses pencarian dalam aplikasi POP tidak dipilih karena tulisan tersebut dalam bentuk 
Artikel Konferensi, Erratum, Catatan, Editorial, Kloning, atau artikel yang tidak disertai dengan abstrak.

Hasil pencarian awal menggunakan aplikasi POP menghasilkan 316 bibliografi, yang kemudian dieliminasi berdasarkan kriteria yang sudah ditentukan sehingga 291 bibliografi yang dipilih dengan cermat dan teliti. Terdapat 25 bibliografi yang dikecualikan karena tidak sesuai dengan kriteria yang telah ditetapkan. Tabel 1 menyajikan jumlah keseluruhan bibliografi per tahun yang dihasilkan dari pencarian melalui aplikasi POP.

Tabel. 1

Hasil Pemilihan Bibliografi

\begin{tabular}{lccccc}
\hline Tahun publikasi & Inklusi & $\%$ & Eklusi & $\%$ & Total \\
\hline $2010-2011$ & 24 & 96 & 1 & 4 & 25 \\
$2012-2013$ & 37 & 88 & 5 & 12 & 42 \\
$2014-2015$ & 59 & 97 & 2 & 3 & 61 \\
$2016-2017$ & 77 & 89 & 9 & 11 & 86 \\
$2018-2019$ & 94 & 92 & 8 & 8 & 102 \\
\hline Total & 291 & & 25 & & 316 \\
\hline
\end{tabular}

Berdasarkan tabel 1 di atas menunjukkan bahwa jumlah publikasi artikel telah meningkat setiap tahun. Ini menunjukkan bahwa kompetensi interprofesional dalam pendidikan keperawatan mendapat perhatian lebih dari para ilmuwan dan peneliti.

\section{Kelengkapan Data Bibliografik}

Untuk melakukan analisis bibliografi yang baik, metadata yang dihasilkan setelah proses pencarian diamati dan diselesaikan secara cermat satu per satu pada seluruh artikel inklusi sebanyak 291 artikel. Pengamatan kelengkapan data mencakup bagianbagian yang akan dianalisis, termasuk judul artikel, nama penulis, negara, abstrak, kata kunci yang digunakan oleh penulis, penerbit, dan tahun publikasi. Setelah metadata lengkap maka dilanjutkan dengan analisis bibliometrik.

\section{Analisis Bibliometrik}

Analisis bibliometrik dilakukan berdasarkan enam karakteristik sebagai berikut; (1) tren publikasi artikel; (2) jurnal yang paling banyak menerbitkan artikel tentang pendidikan interprofesional dan keperawatan; (3) artikel yang paling banyak disitasi/ dikutip; (4) kata kunci sering digunakan penulis dalam artikel tentang pendidikan interprofesional dan keperawatan; (5) profesi kesehatan lain yang paling sering dihubungkan dengan perawat dalam pelaksanaan pendidikan interprofessional; (6) negara asal penulis yang paling banyak mempublikasikan artikel tentang pendidikan interprofesional dan keperawatan. Analisis bibliometrik yang dilakukan dan memvisualisasikan hasil analisis bibliometrik, adalah dengan menggunakan aplikasi VOSviewer. Selain itu, VOSviewer dapat menampilkan peta publikasi, distribusi penulis, atau jurnal berdasarkan platform kutipan bersama atau peta kata kunci secara jelas. Jenis file yang dimasukkan ke dalam aplikasi VOSviewer untuk analisis adalah file bibliografi Mendeley yang diimpor ke file RIS Format dan bibText. 


\section{HASIL PENELITIAN \\ Tren Publikasi}

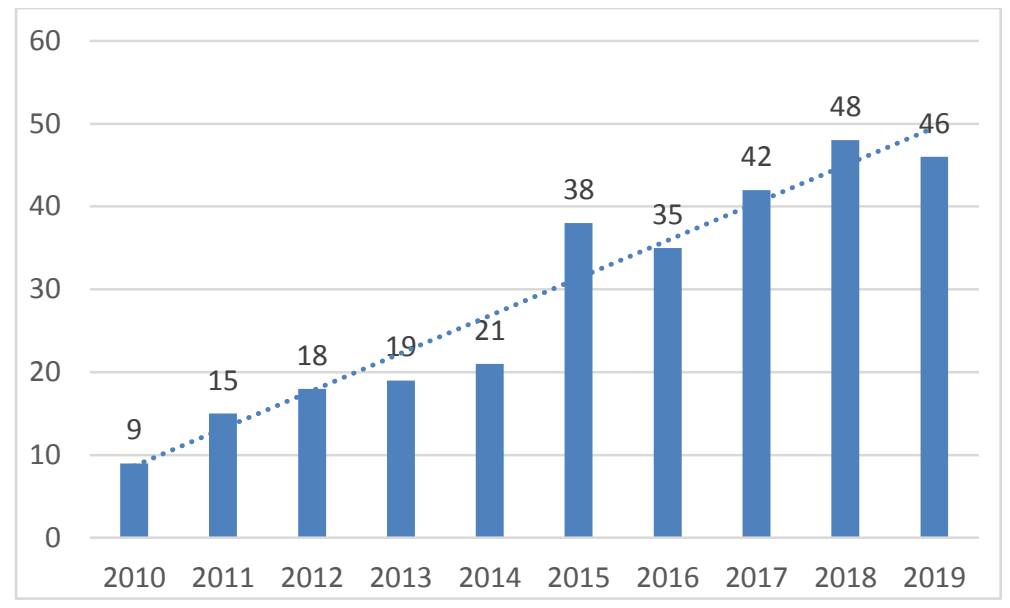

Gambar. 2

Tren Publikasi Artikel Per Tahun

Tren artikel jurnal yang dipublikasikan pada tahun 2010-2019 dengan tema pendidikan antar profesional dan keperawatan. Rata- rata jumlah publikasi artikel per tahun mengalami peningkatan, meskipun terdapat penurunan jumlah publikasi pada beberapa periode, seperti pada tahun 2016 mengalami penurunan apabila kita bandingkan dengan tahun 2015, begitu pula pada tahun 2019 mengalami penurunan dibandingkan tahun 2018. Secara keseluruhan dapat disimpulkan bahwa artikel pendidikan interprofesional dan keperawatan mengalami peningkatan setiap tahunnya.

\section{Jurnal Based Analysis}

Tabel 2 menyajikan 10 besar jurnal dan penerbit yang menerbitkan artikel terbanyak pada periode 2010-2019. Jurnal yang telah menerbitkan artikel terbanyak adalah Journal of Interprofessional Care sebanyak 77 artikel dalam 10 tahun dengan Informa Health Care sebagai penerbitnya. Jurnal kedua yang telah menerbitkan banyak artikel adalah Journal of Interprofessional Education and Practice dengan penerbit Elsevier Inc dengan jumlah total 18 artikel. Hingga saat ini, kesepuluh jurnal yang tercantum dalam tabel tersebut masih tercantum dalam database Scopus. Di peringkat 10 terdapat American Journal of Pharmaceutical Education dengan 6 artikel yang dipublikasikan dalam 10 tahun terakhir.

Tabel. 2

Jurnal dengan Artikel Paling Banyak Diterbitkan tentang Pendidikan Interprofesional

\begin{tabular}{llcl}
\hline No & \multicolumn{1}{c}{ Nama jurnal } & Jumlah artikel & \multicolumn{1}{c}{ Penerbit } \\
\hline 1 & Journal of Interprofessional Care & 77 & Taylor \& Francis \\
2 & Journal of Interprofessional Education and & & Elsevier Inc. \\
& $\begin{array}{l}\text { Practice } \\
3\end{array}$ & 18 & \\
4 & BMC Medical Education & 10 & Springer Nature \\
5 & Journal of Nursing Education & 9 & Slack Incorporated \\
& Currents in Pharmacy Teaching and & 9 & Elsevier Inc. \\
& Learning & &
\end{tabular}




\begin{tabular}{llll}
\hline 6 & Nurse Education Today & 7 & Elsivier Inc. \\
7 & Clinical Simulation in Nursing & 7 & Elsevier Inc. \\
8 & Journal of Allied Health & 7 & Charles B. Slack \\
9 & Nurse Education in Practice & 6 & Elsivier Inc. \\
10 & American Journal of Pharmaceutical & 6 & American \\
& Education & & Association of \\
& & & Colleges of \\
& & & Pharmacy \\
\hline
\end{tabular}

Berdasarkan tabel ini, dapat dilihat bahwa Journal of Interprofessional Care mendominasi jumlah artikel yang diterbitkan sesuai dengan topik pendidikan interprofesional dalam keperawatan. Hal ini sesuai dengan nama jurnal, yang sudah sangat spesifik difokuskan pada pendidikan interprofesional.

\section{Jumlah Sitasi Based Analysis (Rata-Rata Sitasi Per Tahun)}

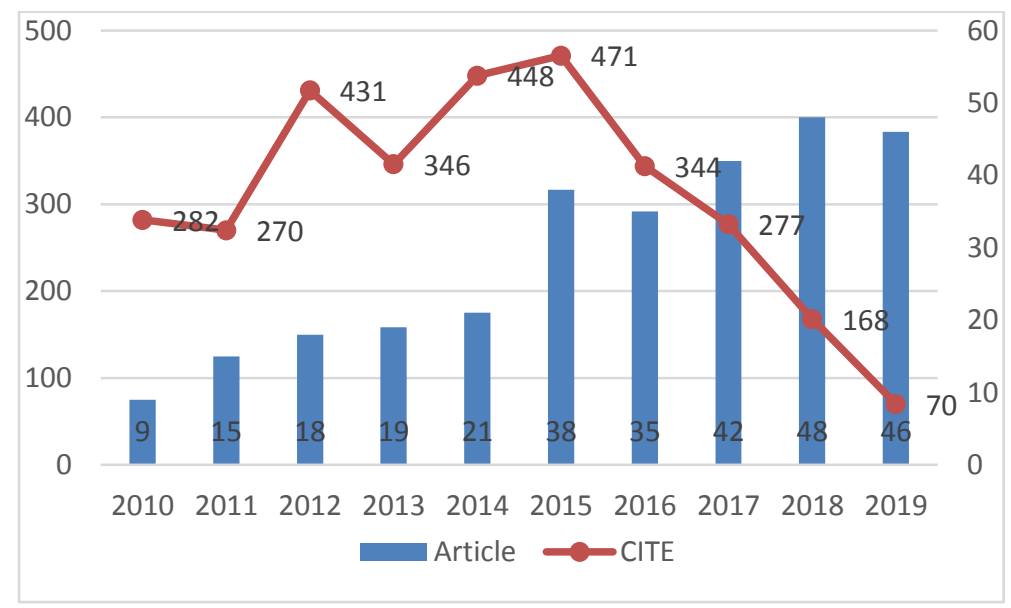

Gambar. 3

Jumlah Sitasi Artikel

Gambar 3 menunjukkan jumlah sitasi artikel tentang pendidikan interprofesional dalam keperawatan per tahun. Pada gambar tersebut menunjukkan bahwa jumlah kutipan artikel per tahun dengan pola yang menurun dan meningkat. Jumlah artikel yang disitasi pada tahun 2011 memiliki pola penurunan dan peningkatan yang cukup signifikan dalam artikel yang diterbitkan pada tahun 2012, 2014 dan 2015, sehingga mencapai puncaknya pada tahun 2015. Dari 38 artikel yang diterbitkan, terdapat 471 artikel yang dikutip. Sementara pada tahun 2016-2019 jumlah kutipan artikel mengalami penurunan setiap tahunnya.

\section{Sepuluh Besar Artikel yang Paling Banyak Disitasi}

Tabel. 2

Artikel dengan Jumlah Sitasi Terbanyak

\begin{tabular}{lllccl}
\hline \multirow{2}{*}{ No } & \multirow{2}{*}{ Penulis } & \multicolumn{1}{c}{ Judul artikel } & $\begin{array}{c}\text { Tahun } \\
\text { Publikasi }\end{array}$ & $\begin{array}{c}\text { Jumlah } \\
\text { Sitasi }\end{array}$ & Nama Jurnal \\
\hline 1 & Joseph & Interprofessional education & 2013 & 132 & Journal of \\
& Zorek .,et & accreditation standards in the & & & Interprofessi \\
& al. & USA: A comparative analysis & & & onal Care \\
\hline
\end{tabular}




\begin{tabular}{|c|c|c|c|c|c|}
\hline 2 & $\begin{array}{l}\text { Barbara } \\
\text { Brandt., } \\
\text { et al. }\end{array}$ & $\begin{array}{l}\text { A scoping review of } \\
\text { interprofessional } \\
\text { collaborative practice and } \\
\text { education using the lens of the } \\
\text { Triple Aim }\end{array}$ & 2014 & 128 & $\begin{array}{l}\text { Journal of } \\
\text { Interprofessi } \\
\text { onal Care }\end{array}$ \\
\hline 3 & $\begin{array}{l}\text { Vernon } \\
\mathrm{R} \\
\text { Curran., } \\
\text { et al. }\end{array}$ & $\begin{array}{l}\text { A longitudinal study of the } \\
\text { effect of an interprofessional } \\
\text { education curriculum on } \\
\text { student satisfaction and } \\
\text { attitudes towards } \\
\text { interprofessional teamwork } \\
\text { and education }\end{array}$ & 2010 & 121 & $\begin{array}{l}\text { Journal of } \\
\text { Interprofessi } \\
\text { onal Care }\end{array}$ \\
\hline 4 & $\begin{array}{l}\text { Sok } \\
\text { YingLia } \\
\text { wa., et al. }\end{array}$ & $\begin{array}{l}\text { An interprofessional } \\
\text { communication training using } \\
\text { simulation to enhance safe } \\
\text { care for a deteriorating } \\
\text { patient }\end{array}$ & 2014 & 92 & $\begin{array}{l}\text { Nurse } \\
\text { Education } \\
\text { Today }\end{array}$ \\
\hline 5 & $\begin{array}{l}\text { Margaret } \\
\text { ha } \\
\text { Wilhelm } \\
\text { sson., et } \\
\text { al. }\end{array}$ & $\begin{array}{l}\text { Are female students in general } \\
\text { and nursing students more } \\
\text { ready for teamwork and } \\
\text { interprofessional } \\
\text { collaboration in healthcare? }\end{array}$ & 2011 & 75 & $\begin{array}{l}\text { BMC } \\
\text { Medical } \\
\text { Education }\end{array}$ \\
\hline 6 & $\begin{array}{l}\text { Conor } \\
\text { Gilligan., } \\
\text { et al. }\end{array}$ & $\begin{array}{l}\text { Recommendations from recent } \\
\text { graduates in medicine, } \\
\text { nursing and pharmacy on } \\
\text { improving interprofessional } \\
\text { education in university } \\
\text { programs: A qualitative study }\end{array}$ & 2014 & 72 & $\begin{array}{l}\text { BMC } \\
\text { Medical } \\
\text { Education }\end{array}$ \\
\hline 7 & $\begin{array}{l}\text { Angus } \\
\text { McFadye } \\
\text { n., et al. }\end{array}$ & $\begin{array}{l}\text { Interprofessional attitudes and } \\
\text { perceptions: Results from a } \\
\text { longitudinal controlled trial of } \\
\text { pre-registration health and } \\
\text { social care students in } \\
\text { Scotland }\end{array}$ & 2010 & 65 & $\begin{array}{l}\text { Journal of } \\
\text { Interprofessi } \\
\text { onal Care }\end{array}$ \\
\hline 8 & $\begin{array}{l}\text { Suzanne } \\
\text { Gough., } \\
\text { et al. }\end{array}$ & $\begin{array}{l}\text { A review of undergraduate } \\
\text { interprofessional simulation- } \\
\text { based education (IPSE) }\end{array}$ & 2012 & 58 & Collegian \\
\hline 9 & $\begin{array}{l}\text { Moira } \\
\text { Stewart., } \\
\text { et al. }\end{array}$ & $\begin{array}{l}\text { Undergraduate } \\
\text { interprofessional education } \\
\text { using high-fidelity paediatric } \\
\text { simulation }\end{array}$ & 2010 & 46 & $\begin{array}{l}\text { Clinical } \\
\text { Teacher }\end{array}$ \\
\hline 10 & $\begin{array}{l}\text { Courtney } \\
\text { West., et } \\
\text { al. }\end{array}$ & $\begin{array}{l}\text { Implementation of } \\
\text { interprofessional education } \\
(I P E) \text { in } 16 \text { U.S. medical } \\
\text { schools: Common practices, } \\
\text { barriers and facilitators }\end{array}$ & 2016 & 46 & $\begin{array}{l}\text { Journal of } \\
\text { Interprofessi } \\
\text { onal } \\
\text { Education } \\
\text { and Practice }\end{array}$ \\
\hline
\end{tabular}

Tabel 3 menyajikan data 10 artikel teratas tentang pendidikan interprofesional dalam keperawatan yang telah disitasi paling banyak dalam tahun 2010-2019. Artikel yang menduduki peringkat pertama ditulis oleh Zorek., dkk dan diterbitkan pada tahun 2013 dengan disitasi 132 kali. Peringkat kedua dan ketiga adalah artikel yang ditulis oleh Brant., dkk dan Curran., dkk dengan jumlah masing-masing disitasi sebanyak 128 dan 121 kali. Posisi keempat dengan jumlah sitasi masih di atas 100 kali adalah artikel yang ditulis oleh YingLiawa., dkk. Hanya di peringkat 9 dan 10 yang disitasi kurang dari 50, yaitu artikel yang ditulis oleh Stewart., et.al dan West., dkk 


\section{Negara Asal Penulis}

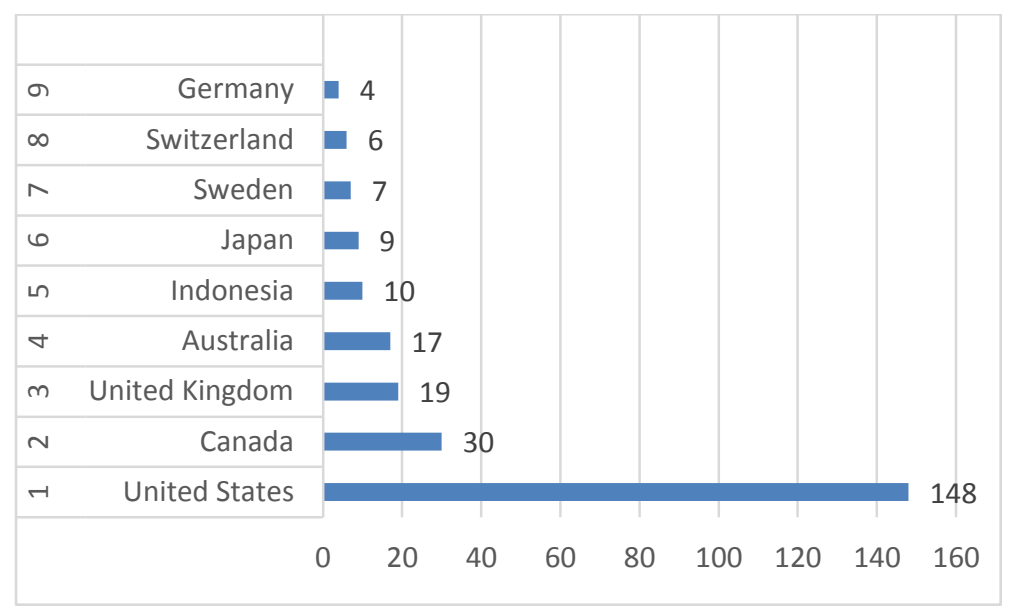

Gambar. 4

Negara Asal Penulis

Amerika Serikat adalah negara dengan penulis terbanyak yang menulis artikel tentang pendidikan interprofesional dalam keperawatan seperti halnya digambarkan pada gambar 10, dengan jumlah artikel 138. Pada posisi kedua adalah negara Kanada dan diikuti oleh Inggris dengan masing-masing 30 dan 19 artikel dalam 10 tahun terakhir. Indonesia dan Jepang adalah negara-negara di kawasan Asia yang berada di posisi ke-5 dan ke-6 dengan jumlah artikel yang diterbitkan, masing-masing 10 dan 9 . Di posisi ke 9, Jerman adalah negara terakhir dengan 4 artikel yang diterbitkan.

\section{Tenaga Kesehatan Professional Lain yang Sering Dihubungakn dengan Perawat}

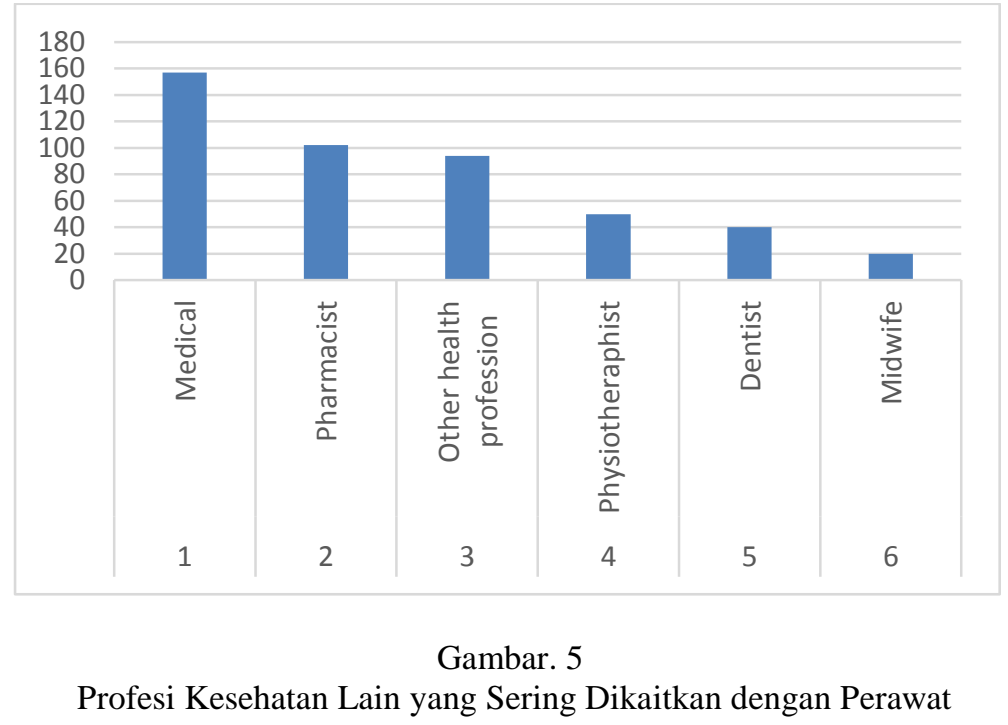

Gambar 5 menyajikan profesi kesehatan lain yang dihubungkan atau dikaitkan dengan perawat dalam artikel interprofesional dalam keperawatan. Profesi kesehatan lain yang paling sering dikaitkan dengan perawat dalam artikel pendidikan interprofesional adalah dokter, urutan kedua adalah apoteker. Di posisi ketiga adalah 
profesi kesehatan lainnya seperti terapis kerja, pekerja sosial, dan kesehatan masyarakat. Sementara itu, dalam urutan profesi kesehatan paling sedikit yang terkait dengan perawat adalah bidan.

\section{Jumlah Profesi Kesehatan yang Dilibatkan sebagai Responden Selain Perawat}

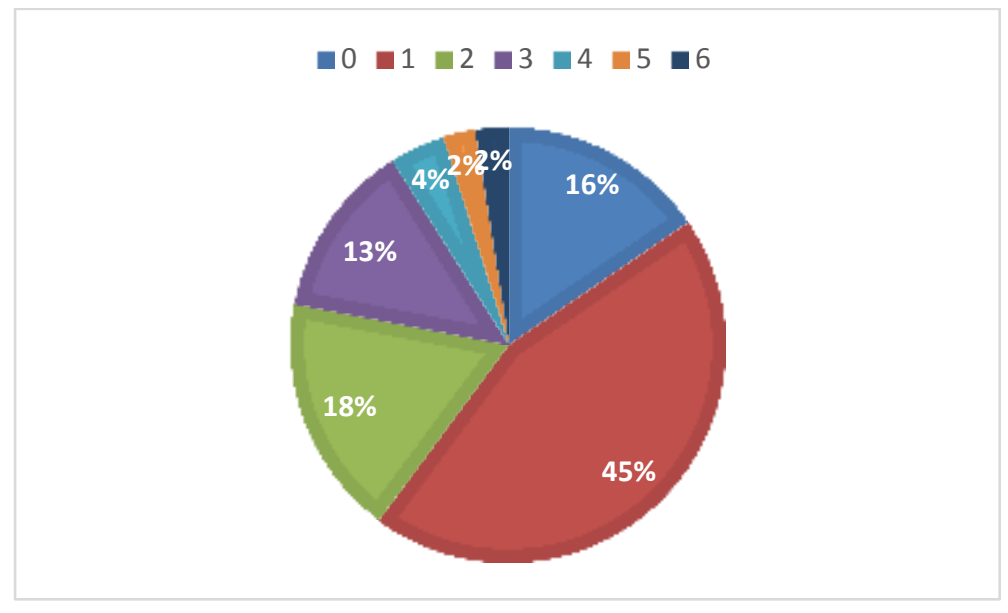

\section{Gambar 6.}

Jumlah jenis profesi kesehatan yang dilibatkan sebagai responden

Hasil penelitian ini juga menyajikan data jumlah profesi yang terlibat dalam setiap jurnal artikel pendidikan antarprofesi dengan jumlah tertinggi, yaitu hampir setengah (45\%) dari semua artikel (291) yang melibatkan 1 profesi kesehatan dengan keperawatan sebagaimana diilustrasikan dalam Gambar 6. Pada posisi kedua melibatkan 2 profesi kesehatan (18\%). Sementara itu, jumlah paling sedikit (2\%) hanya melibatkan 2-3 profesional kesehatan. Juga dapat dilihat bahwa ada sekitar 4\% anggota yang hanya fokus membahas pendidikan antarprofesi dalam profesi keperawatan.

\section{Kata Kunci Penulis Based Analysis}

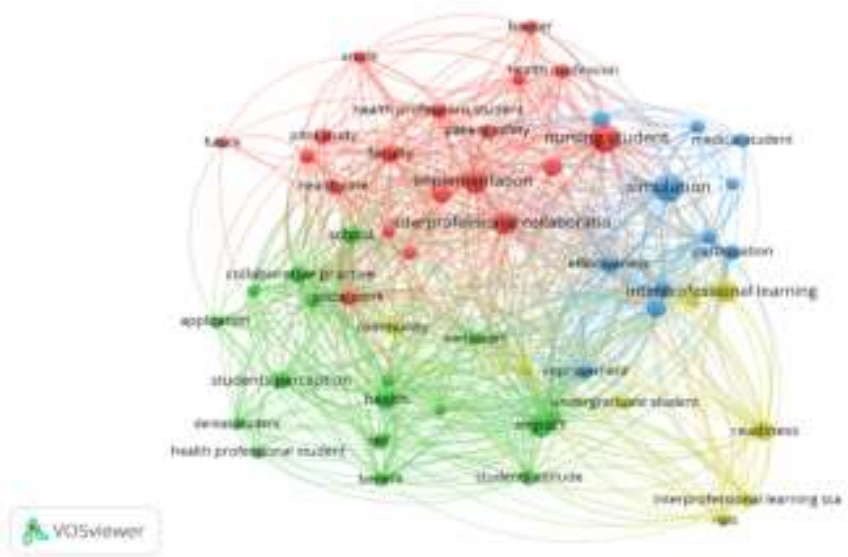

Gambar. 7

Network Visualization of Author Keyword 
Analisis kata kunci penulis dilakukan melalui aplikasi VOSviewer. Gambar 7 ditampilkan, 55 kata kunci penulis yang dibuat sangat terhubung. Kata kunci penulis 55 dipisahkan menjadi 4 kluster yang ditawarkan oleh warna yang berbeda. Klaster 1 (merah) terdiri dari 19 item, klaster 2 (hijau) terdiri dari 17 item, klaster 3 (biru) terdiri dari 11 item, dan cluster 4 (kuning) terdiri dari 8 item.

\section{PEMBAHASAN}

Pendidikan interprofesional merupakan pendekatan pedagogis yang sangat penting untuk mempersiapkan mahasiswa profesi kesehatan agar dapat melakukan tindakan kolaboratif dalam melakukan perawatan pasien. IPE bukanlah sesuatu yang baru dalam pendidikan profesional kesehatan, ini dibuktikan dengan ditemukannya artikel yang berkaitan dengan IPE pada tahun 1969 berjudul "Pendidikan interprofessional dalam ilmu kesehatan"(Fransworth et al., 2015). Namun, kompetensi IPE mulai diperhatikan dengan serius pada tahun 2010 setelah WHO menerbitkan framework Pendidikan Interprofesional yang didalamnya terdapat penjelasan bahwa IPE harus menjadi salah satu kompetensi yang dikuasai oleh semua profesi kesehatan. WHO mengusulkan sistem pendidikan yang akan mendorong pembelajaran interprofesional dengan mereka yang berada di luar disiplin ilmunya sebagai sarana untuk menyempurnakan kualitas dan efektivitas perawatan kesehatan di seluruh dunia. Menurut pandangan WHO, tujuan pendidikan interprofessional adalah untuk mempersiapkan semua mahasiswa profesi kesehatan agar secara sadar dapat bekerja sama dan berkolaborasi untuk mencapai tujuan bersama yaitu membangun sistem perawatan kesehatan yang lebih aman, komprehensif, dan lebih baik.

Berdasarkan hal tersebut, kami mencari metadata artikel jurnal tentang pendidikan interprofesional dalam keperawatan yang diterbitkan pada tahun 2010-2019. Dalam rentang waktu tersebut (10 tahun), diperoleh sebanyak 291 artikel jurnal. Terdapat peningkatan jumlah artikel yang diterbitkan setiap tahun, meskipun dalam beberapa periode telah terjadi penurunan jumlah publikasi yaitu pada tahun 2016 dan 2019. Publikasi artikel jurnal telah meningkat karena ada beberapa faktor yang mempengaruhinya, faktor struktural (seperti bagaimana pengelolaan pendidikan dalam suatu instutusi pendidikan terutama dalam hal kewajiban publikasi jurnal) dan juga terdapat faktor internal individu (seperti minat intrinsik diri seseorang sesuai dengan disiplin keilmuan yang dimilikinya) untuk menentukan tingkat produktivitas publikasi jurnal.

Sepuluh jurnal teratas yang menerbitkan artikel tentang pendidikan interprofesional dalam keperawatan adalah jurnal terkemuka dan diindeks oleh Scopus dengan kuartil Q1 dan Q3 hanya satu jurnal dengan kuartil Q4. Jurnal-jurnal ini juga diterbitkan oleh penerbit yang kredibel dan bereputasi baik. Berdasarkan studi mendalam oleh para peneliti bahwa sepuluh jurnal tersebut masih diindeks oleh Scopus hingga waktu dilakukan analisis data (4 Desember 2020). Para akademisi dan peneliti masih sangat percaya bahwa faktor-faktor yang mempengaruhi kualitas artikel masih ditentukan oleh jurnal mana yang akan menerbitkan, termasuk penerbit yang kredibel yang mempengaruhi pilihan dimana jurnal akan diajukan. Peneliti membutuhkan konten yang disunting dengan baik dan berkualitas tinggi. Jurnal berkualitas buruk dan predator adalah ancaman bagi integritas suatu ilmu pengetahuan. Sebuah artikel telah berkontribusi dan berdampak pada pengembangan ilmu pengetahuan atau kelompok lain, salah satu indikatornya adalah berapa banyak artikel itu disitasi oleh penulis lain. 
Artikel yang ditulis oleh Zorek merupakan artikel yang paling banyak dikutip, yaitu 132 kali, artikel ini diterbitkan pada tahun 2013 di Interprofessional Care Journal, yang merupakan salah satu jurnal internasional terkemuka dan bereputasi baik dengan Scopus Quartil Q1. Dalam artikel ini, para peneliti melibatkan lebih dari 6 profesi kesehatan, sehingga pendidikan interprofesional dapat dilihat lebih komprehensif dari berbagai profesi kesehatan (Zorek, 2013). Pada urutan ke sepuluh terdapat artikel yang ditulis oleh West., Et al. diterbitkan pada tahun 2016 oleh Journal of Interprofessional Education and Practice dengan Scopus Quartil Q1, dan telah dikutip sebanyak 46 kali. Kutipan juga digunakan untuk menganalisis metrik seperti Journal Impact Factor (JIF) (Malhotra et al., 2018) . Editor jurnal ilmiah dapat mencari naskah yang menarik dengan kemungkinan untuk mendapatkan jumlah kutipan tinggi, hal ini biasanya dilakukan untuk meningkatkan JIF pada jurnal yang mereka kelola, mereka memperluas status mereka, dan memilih naskah terbaik di masa depan (Falagas \& Alexiou, 2008; Jawaid \& Jawaid, 2018; Watson et al., 2013).

Tren mengutip artikel jurnal setiap tahun telah meningkat, hal ini menunjukkan bahwa minat penelitian juga meningkat pada topik pendidikan interprofesional dalam keperawatan. Gambar 4 menunjukkan negara-negara asal penulis dengan artikel jurnal yang paling banyak diterbitkan adalah Amerika Serikat dengan 142 artikel, Kanada 30 artikel, dan Inggris 19 artikel dalam 10 tahun terakhir. Fakta yang ada pada saat ini bahwa peringkat $Q S$ World University Rankings for Nursing dibangun berdasarkan pendapat ahli dari ribuan akademisi dan pengusaha, secara bersama melakukan analisis pada 247.910 makalah penelitian yang berkaitan dengan keperawatan dan QS Quacquarelli Symonds ini mulai dijadikan sebagi salah satu faktor analisis pada sektor pendidikan tinggi sejak tahun 1990. QS Quacquarelli Symonds ini mempublikasikan peringkat universitas di seluruh dunia dan mencakup lebih dari 40 bidang studi yang berbeda pada setiap tahunnya di situs webnya dan Amerika Serikat, Kanada, dan Inggris negara dengan tiga besar dengan universitas ternama di dunia (Rankings Reveal Best Places to Study Nursing around the World, n.d.).

Ada sesuatu yang menarik perhatian penulis di sini bahwa Indonesia berdasarkan QS World University Ranking tidak termasuk dalam 100 besar, tetapi dalam artikel tentang topik pendidikan interprofesional dalam keperawatan yang dicari penulis dalam penelitian ini ternyata berada di peringkat ke-5. Situasi kemungkinan besar terjadi dikarenakan adanya regulasi, aturan serta kebijakan pemerintah Indonesia yang mengharuskan dosen/peneliti untuk mempublikasikan hasil penelitiannya sehingga hal ini dimungkinkan menjadi faktor penting dalam peningkatan jumlah publikasi artikel yang ditulis oleh peneliti/akademisi asal Indonesia di tingkat internasional. Hal ini merupakan satu upaya untuk mendorong dan memotivasi dosen/peneliti agar dapat menulis artikel lebih baik dan dapat menerbitkan artikel ilmiah tersebut di jurnal internasional dan memberikan reward juga apresiasi kepada para penulis.

Profesi kesehatan yang paling sering dikaitkan dengan perawat dalam pendidikan interprofesional ini adalah dokter, apoteker dan fisioterapis. Pelayanan kesehatan di rumah sakit, puskesmas, dan masyarakat profesional harus selalu berkolaborasi dalam bekerja. Dokter dan perawat adalah populasi tenaga kesehatan terbesar di dunia, diikuti oleh kebidanan dan fisioterapis (WHO, 2019), sehingga pada artikel-artikel profesi perawat dan dokter adalah yang paling sering muncul seperti yang disajikan pada gambar 6. Gambar 7 memperlihatkan kata kunci penulis, dan hubungannya dengan kata kunci penulis lainnya. Ada 4 klaster mulai dari klaster tertinggi, yaitu berwarna merah, klaster kedua berwarna hijau, klaster ketiga berwarna biru, dan klaster terakhir berwarna 
kuning. Kluster tertinggi menunjukkan bahwa kata kunci ini sering muncul di artikel. Kata kunci yang sering muncul adalah mahasiswa keperawatan, implementasi dan kolaborasi.

\section{SIMPULAN}

Pendidikan antarprofesional telah mendapat perhatian lebih dalam 10 tahun terakhir. Hal ini dibuktikan dengan fakta bahwa penulis menemukan cukup banyak artikel hanya dalam satu sumber metadata, yaitu Scopus. Sejak WHO menerbitkan kerangka kerja pendidikan interprofesional, tren penerbitan artikel tentang topik ini terus meningkat. Demikian juga, jumlah kutipan artikel meningkat, dan 10 jurnal teratas memiliki reputasi yang sangat baik dengan rentang kuartil Scopus Q1-Q3. Negara negara dengan tingkat publikasi tertinggi didominasi oleh negara-negara maju, yaitu Amerika Serikat, Kanada dan Inggris. Dokter dan apoteker adalah profesi yang paling sering dikaitkan dengan perawat dalam pendidikan interprofesional. Dan akhirnya, kata kunci penulis yang paling sering muncul dalam artikel adalah mahasiswa keperawatan, implementasi dan kolaborasi.

\section{SARAN}

Berdasarkan hasil penelitian ternyata di Indonesia sudah banyak penelitian tentang IPE dalam 10 tahun terakhir, tetapi masih cukup sedikit penelitian IPE yang berkaitan dengan keperawatan, oleh sebab itu sangat berpeluang sekali untuk meneliti IPE dalam implementasi pendidikan keperawatan di Indonesia mengingat latar belakang budaya Indonesia juga yang akan berpengaruh terhadap kompetensi kolaborasi perawat dengan profesi Kesehatan lain.

\section{DAFTAR PUSTAKA}

Bar, M. A., Leurer, M. K., Warshawski, S., \& Itzhaki, M. (2017). The Role of Personal Resilience and Personality Traits of Healthcare Students on Their Attitudes Towards Interprofessional Collaboration. Nurse Educ Today, 61, 36-42 https://doi.org/10.1016/j.nedt.2017.11.005

Batanero, J. M. F., Rebollo, M. M. R., \& Rueda, M. M. (2019). Impact of ICT on Students with High Abilities. Bibliographic Review (2008-2018). Computers and Education, 137(January), 48-58. https://doi.org/10.1016/j.compedu.2019.04.007

Blaževičienè, A., Vanckavičienè, A., Paukštaitiene, R., \& Baranauskaite, A. (2021). Nurse's Role from Medical Students' Perspective During Their Interprofessional Clinical Practice: Evidence from Lithuania. Healthcare (Switzerland), 9(8). https://doi.org/10.3390/healthcare 9080963

Christopher, A., Gortemiller, T., Zemmer, J., \& Wronowski, M. (2021). Interprofessional Healthcare Student Perceptions of Clinical vs. Simulation Learning Through Participation in Underserved Health Clinics. Medical Science Educator, 31(4), 1291-1304. https://doi.org/10.1007/s40670-021-01297-9

Falagas, M. E., \& Alexiou, V. G. (2008). The Top-Ten in Journal Impact Factor Manipulation. In Archivum Immunologiae et Therapiae Experimentalis, 56(4), 223-226. Springer. https://doi.org/10.1007/s00005-008-0024-5

Fransworth, T., Seikel, J., Hudock, D., \& Holst, J. (2015). History and Development of Interprofessional Education. https://doi.org/10.4172/2471-9455.1000101 
Homeyer, S., Hoffmann, W., Hingst, P., Oppermann, R. F., \& Dreier-Wolfgramm, A. (2018). Effects of Interprofessional Education for Medical and Nursing Students: Enablers, Barriers and Expectations for Optimizing Future Interprofessional Collaboration-A Qualitative Study. BMC Nursing, 17(1), 1-10. https://doi.org/10.1186/s12912-018-0279-x

Iverson, L., Bredenkamp, N., Carrico, C., Connelly, S., Hawkins, K., Monaghan, M. S., \& Malesker, M. (2018). Development and Assessment of an Interprofessional Education Simulation to Promote Collaborative Learning and Practice. The Journal of Nursing Education, 57(7), 426-429. https://doi.org/10.3928/0148483420180618-08

Jawaid, S. A., \& Jawaid, M. (2018). Impact Factor is Off the Ventilator: Survives and is Thriving. In Pakistan Journal of Medical Sciences, 34(6), 1317-1319. https://doi.org/10.12669/pjms.346.16652

Julia, J., Dolifah, D., Afrianti, N., Isrokatun, I., Soomro, K. A., Erhamwilda, E., Supriyadi, T., \& Ningrum, D. (2020). Flipped Classroom Educational Model (2010-2019): A Bibliometric Study. European Journal of Educational Research, 9(4), 1377-1392. https://doi.org/10.12973/eu-jer.9.4.1377

Lestari, E. (2018). Community Based Interprofessional Learning Promotes Equality of Participation among Health Professions Students. Online Journal of Health and Allied Sciences, $17(2)$. https://www.scopus.com/inward/record.uri?partnerID=HzOxMe3b\&scp=8505205 2183\&origin=inward

Malhotra, K., Saeed, O., Goyal, N., Katsanos, A. H., \& Tsivgoulis, G. (2018). Top-100 Highest-Cited Original Articles in Ischemic Stroke: A Bibliometric Analysis. World Neurosurgery, 111, e649-e660. https://doi.org/10.1016/j.wneu.2017.12.140

Peduzzi, M., Aguiar, C., Lima, A. M. V., Montanari, P. M., Leonello, V. M., \& Oliveira, M. R. (2019). Expansion of the Interprofessional Clinical Practice of Primary Care Nurses. Revista Brasileira de Enfermagem, 72(Suppl 1), 114-121. https://doi.org/10.1590/0034-7167-2017-0759

Spaulding, E. M., Marvel, F. A., Jacob, E., Rahman, A., Hansen, B. R., Hanyok, L. A., Martin, S. S., \& Han, H. R. (2021). Interprofessional Education and Collaboration Among Healthcare Students and Professionals: A Systematic Review and Call for Action. Journal of Interprofessional Care, 35(4), 612-621. https://doi.org/10.1080/13561820.2019.1697214

Vestergaard, E., \& Nørgaard, B. (2018). Interprofessional Collaboration: An Exploration of Possible Prerequisites for Successful Implementation. Journal of Interprofessional Care, $32(2)$,

185-195. https://doi.org/10.1080/13561820.2017.1363725

Watson, R., Cleary, M., \& Hunt, G. E. (2013). What Gets Highly Cited in JAN? Can Editors Pick Which Articles Will Contribute to a Journal's Impact Factor? Journal of Advanced Nursing, 69(11), e30-e34. https://doi.org/10.1111/jan.12261

WHO. (2019). WHO | Nursing and midwifery. WHO. http://www.who.int/hrh/nursing_midwifery/en/

Zorek, J. (2013). Interprofessional Education Accreditation Standards in the USA: A Comparative Analysis. Journal of Interprofessional Care, 27(2), 123-130. https://doi.org/10.3109/13561820.2012.718295 